\title{
TRABALHO E EDUCAÇÃO NA NOVA ORDEM CAPITALISTA: INOVAÇÃO TÉCNICA, QUALIFICAÇÃO E PRECARIZAÇÃO
}

\author{
Fabiane Santana Previtali ${ }^{\mathrm{i}}$ \\ Cílson César Fagianii
}

\begin{abstract}
RESUMO
$\mathrm{O}$ artigo analisa a relação entre trabalho e educação, em particular o processo de inovação tecnológica e as demandas do mercado para requisitos de maior qualificação da força de trabalho. A pesquisa está em andamento e corresponde à tese de pós-doutoramento e de doutoramento dos autores respectivamente. A metodologia utilizada é a revisão de literatura, análise de documentos oficiais, como os fornecidos pela OCDE e OIT, e dados estatísticos de fontes oficiais europeias e dos Estados Unidos a partir dos anos 1990. Os resultados são ainda parciais e apontam para o crescimento da classe trabalhadora no mundo capitalista, com destaque nos países da comunidade europeia e Estados Unidos ao longo da década de 1990 e início do século XXI. No entanto, tal crescimento encontra-se assentado em relações laborais cujas características prevalecentes são a qualificação profissional e o emprego flexível acompanhado de achatamento salarial.

Palavras-chave: Inovação Tecnológica; Trabalho; Qualificação; Precarização.
\end{abstract}

\section{WORK AND EDUCATION IN THE NEW ORDER CAPITALIST: TECHNICAL INNOVATION, QUALIFICATION AND PRECARIOUSNESS}

\begin{abstract}
The paper examines the relationship between work and education, in particular the process of technological innovation and market demands for higher qualification requirements of the workforce. The research is ongoing and corresponds to the thesis of post-doctoral and doctoral authors respectively. The methodology used is a literature review, analysis of official documents, such as those provided by the OECD and ILO, and statistical data of European officials and the United States from the 1990s. The results are still partial but the growth of the working class in the capitalist world, especially in countries of the European community and the United States throughout the 1990s and early twenty-first century can be observed. However, this growth is founded on labor relations that have the characteristics such as professional qualifications, flexible employment and wage flattening.
\end{abstract}

Keywords: Technological Innovation; Labor; Qualification; Precariousness.

\section{INTRODUÇÃO}

A era da acumulação flexível (HARVEY, 1992; HARVEY, 2011) acarretou profundas modificações no mundo do trabalho entre elas um enorme desemprego estrutural e um crescente contingente de trabalhadores em condições de precarização e superexploração, modificações estas conduzidas pela lógica societal voltada para a produção de mercadorias e para a valorização do capital (THOMPSON, 2010; MILKMAN; LUCE, 2013; CARTER et al, 2014). 
Com a crise que se instaura na acumulação taylorista-fordista a partir da segunda metade da década de 1970 impõe-se para as empresas a necessidade de encontrar uma força de trabalho mais complexa, mais heterogênea e mais multifuncional para ser explorada de forma mais intensa e sofisticada pelo capital (ANTUNES, 2000; ANTUNES, 2002, ANTUNES, 2013). Assim, o processo de reestruturação produtiva das empresas nada mais é que a reestruturação do capital, visando assegurar sua expansão e acumulação.

A cada passo dado na introdução de inovações técnicas e/ou organizacionais, há uma oportunidade para a destruição de formas de resistência ao controle do trabalho à exploração (MILKMAN, 1997; BIHR, 1998; MILKMAN; LUCE, 2013). Cada vez mais as empresas beneficiam-se da desregulamentação neoliberal do trabalho para modificar suas relações com a classe trabalhadora via intensificação dos processos de flexibilização envolvendo práticas como a da terceirização e subcontratação, do trabalho temporário e do trabalho em grupo e impondo fortes derrotas ao movimento sindical que havia nascido sob as práticas tayloristas-fordistas. Para Harvey (2011, p. 16), "o neoliberalismo legitima práticas draconianas destinadas a restaurar e consolidar o poder da classe capitalista".

As teses liberalizantes, manifestas na centralidade do mercado como agente regulador e do declínio do Estado, demonstram uma crescente concentração de capital sob o poder de bancos privados e empresas transnacionais à custa do retrocesso de direitos historicamente conquistados pela classe trabalhadora.

O pensamento liberal está presente desde a década de 1940, sendo Hayek (2010) um de seus maiores defensores. No entanto, é a partir dos anos 1990 que começa a ser hegemônico no mundo. Segundo Caggiola e Martins (2006), com a mundialização/globalização e o desenvolvimento da economia do rentista internacional, os Estados se endividaram tomando grandes somas emprestadas de instituições financeiras para pagar juros aos rentistas a taxas estabelecidas por outro braço do governo, os bancos centrais. $\mathrm{O}$ acúmulo de grandes dívidas públicas conferiu aos interesses financeiros e bancários o poder de direcionar a política social e econômica, processo originado na sobre acumulação de capital.

Dessa forma, explicam os autores, passa a existir um excesso de capital que não consegue valorização nos moldes tradicionais, isto é, por meio da produção crescente de valores, com posterior venda/realização da mais-valia neles contida, em mercados também em expansão, sendo necessário encontrar outra esfera para que esse capital produzido em excesso conseguisse valorizar-se.

A reforma do Estado assenta-se nos relatórios e diagnósticos do Banco Mundial, do Fundo Monetário Internacional (FMI) e da Organização para a Cooperação e o Desenvolvimento Económico (OCDE). Tais organizações, em particular o FMI, propõem o aumento da desregulação, a diminuição da burocracia do Estado e a redução das suas contas e orçamentos como receita para estancar as crises econômicas, assim como as crises dos sistemas públicos de educação e de proteção social (GRANEMANN, 2008).

Tendo em vista esse quadro, o artigo analisa o processo de inovação técnica no processo produtivo capitalista à luz da teoria marxista e tomando como referência para o debate a crítica à escola neo-schumpteriana, fundamentalmente os autores Christopher Freedman e Carlota Perez. A síntese desse debate indica que o limite da abordagem neoschumpeteriana está em não articular a mudança técnica à lei do valor, que é o que fundamenta historicamente o dinamismo tecnológico na ordem do capital. Os dados empíricos apresentados apontam para o crescimento da classe trabalhadora no mundo capitalista ao longo da década de 1990 e início do século XXI, porém, tal crescimento 
encontra-se assentado em novas relações laborais cujas características prevalecentes são o emprego flexível acompanhado de achatamento salarial e o discurso à qualificação.

\section{INOVAÇÃO TÉCNICA E TRABALHO NO CAPITALISMO}

$\mathrm{Na}$ visão de autores neo-schumpeterianos, com destaque para Freeman; Perez (1988), Perez (2002 e 2010), Mazzucato; Perez (2014) a difusão de uma tecnologia está associada ao potencial que ela tem de transformar os setores da economia, as sim como induzir à formação de novos setores, levando ao desenvolvimento de um novo paradigma técnico-econômico e constituindo um novo ciclo de desenvolvimento. $\mathrm{O}$ processo de inovação consiste, por um lado, no início de uma crise e, por outro lado, na sua recuperação à medida que os setores industriais, bem como as estruturas sócioinstitucionais, vão adequando-se às inovações. Nas palavras de Freeman; Perez (1988: 59):

[...] é evidente que este é um período de transição caracterizado por uma profunda mudança estrutural na economia que requer transformações igualmente profundas nas instituições sociais. O quadro de uma recessão prolongada tende a indicar o crescente grau da má combinação entre o subsistema técnico-econômico e a velha estrutura sócio-institucional.

O regime tecnológico que predominou no pós-guerra, o taylorismo-fordismo, baseou-se nos baixos custos do petróleo e intensiva utilização de energia de materiais nos setores econômicos, particularmente o setor automotivo (MILKMAN, 1997; BIHR, 1998; MILKMAN; LUCE, 2013). Do ponto de vista da organização, em nível da planta difundiuse a linha de montagem e, em nível da empresa difundiu-se a grande corporação, incluindo departamentos de pesquisa e desenvolvimento (P\&D) e atuando em mercados oligopolizados. Quanto ao trabalho, esse regime requeria grande número de trabalhadores pouco qualificados, o chamado "operário-massa", realizando tarefas parcelares, desprovidas de conteúdo e sentido para o trabalhador.

Ainda segundo a abordagem neo-schumpeteriana, a partir do final da década de 1970, as economias capitalistas avançadas iniciaram uma fase de transição para um novo paradigma tecnológico uma vez que um tipo de insumo básico, a tecnologia de base microeletrônica, passou a ser difundido rapidamente pelos setores econômicos. O período de nascimento de um novo paradigma é caracterizado pelos autores como de "transição", no qual as mudanças econômicas requerem mudanças na estrutura institucional que, até então, adequava e regulava as relações sociais, econômicas e políticas no velho paradigma. No que se refere ao trabalho, destaca-se a formação de um mercado de trabalho mais flexível com exigências de maiores níveis de escolaridade e de novas habilidades.

Para esses autores, a crise nada mais é que um período de ajustamento em que mudanças sociais e políticas, em âmbito institucional, são necessárias para a consolidação do novo paradigma e para a regulação da nova ordem, pautada nas tecnologias microeletrônicas e de informação. Partilhando dessas visões e com vistas à promoção de um mercado de trabalho mais flexível, os governos de diversos Estados vêm desenvolvendo políticas neoliberais de ajuste econômico e social que impactam diretamente na classe trabalhadora, retirando direitos duramente conquistados via desregulamentação das relações laborais e redução da seguridade social.

Observa-se um intenso processo de reestruturação produtiva do capital através da integração dos mercados financeiros, fundamentado, por sua vez, no novo ideário político neoliberal de livre comércio e de uma menor presença do Estado como poder regulador das 
relações entre capital e trabalho. Nesse contexto, dados da OIT (2012) mostram que a taxa de pobreza aumentou na metade dos países economicamente desenvolvidos e em 1/3 dos países de economia em desenvolvimento. A desigualdade também se elevou na metade dos países de economia desenvolvida e em um quarto nos países de economias em desenvolvimento.

Ocorre que para os neo-schumpeterianos, a tecnologia assume uma posição de independência e autonomia sobre as relações sociais e institucionais, conferindo um caráter determinista e de neutralidade à explicação de um processo que não é somente técnico, mas de transformação social (TOMANEY, 1996; PREVITALI; FARIA, 2008). A relação entre mudança técnica e ajuste sócio institucional confere uma posição de subordinação desta última à primeira, o que torna o conjunto das relações socioculturais e de classe dependentes de atributos técnicos, quando, na realidade, a técnica insere-se no contexto mais amplo do modo de produção capitalista e sua forma de acumulação (ANTUNES, 2002; ANTUNES, 2013).

Cumpre destacar que no capitalismo o processo de trabalho consiste em um processo de valorização do capital, sendo o seu objetivo principal o aumento da produção da mais valia. A questão que se coloca para o capital é a de como aumentar a produção da mais valia independentemente do prolongamento da jornada de trabalho. Esse processo torna-se possível através da redução do tempo de trabalho necessário - a parte do tempo que o trabalhador utiliza para si mesmo - e aumento do mais trabalho, que corresponde ao tempo de trabalho para o capitalista. Dessa forma o capital aumenta a força produtiva do trabalho "mediante mudanças nos meios de trabalho ou nos métodos de trabalho ou em ambos" (MARX, 1988: 238) e o processo de valorização do capital passa a se estabelecer através da mais valia relativa.

Portanto, o capital realiza a mais valia relativa através de um processo de mudanças nos meios de produção e métodos de organização do trabalho por meio da aplicação da tecnologia, que por sua vez, reduz o valor da mercadoria e da força de trabalho. Há um estímulo individual do capitalista para a redução do tempo de trabalho necessário que é o barateamento da mercadoria devido à concorrência dos demais capitalistas. A concorrência, assim, impele o capitalista a transformar as condições técnicas e organizacionais do processo de trabalho através da apropriação do saber dos trabalhadores (MARX, 2010).

Nesse sentido, o capitalista que introduz as inovações no processo produtivo tem a possibilidade de apropriar-se de maior parte da jornada de trabalho para o mais trabalho do que os demais capitalistas que ainda não o fizeram. Entretanto, essa mais valia extra, obtida quando o capitalista individual consegue obter maior lucro que os demais, desaparece à medida que a inovação se generaliza na economia capitalista (MARX, 2010). $\mathrm{O}$ aumento da força produtiva do trabalho estende-se pelos ramos da produção, por um lado, barateando a mercadoria e, por outro lado, reduzindo o valor da força de trabalho.

Há, dessa forma, um estímulo intrínseco ao modo de produção capitalista que faz com que o capitalista queira investir em novas técnicas de produção e organização do trabalho, alterando o conjunto das forças produtivas (MARX, 2010). Submetida à lógica dos interesses do capital, a ciência, transformada em tecnologia, se converte numa poderosa alavanca de exploração do trabalho e, portanto, de reprodução do capital em escala ampliada (MARX, 1988; BRAVERMAN, 1981; ANTUNES, 2002; ANTUNES, 2013; CARTER, et al, 2014). 
Tem-se assim, uma complexa e contraditória inter-relação entre ciência e valor na medida em que seu potencial é limitado pela sua determinação de classe. Nesse sentido, de acordo com Antunes (2002: 54):

[...] as teses que argumentam sobre a preponderância da ciência e da técnica como forças produtivas nas sociedades contemporâneas são passíveis de críticas, pois, ao mesmo tempo em que a ciência é liberada pelo capital para expandir-se ela é, em última instância, subordinada aos imperativos do processo de criação de valores de troca.

Para o autor, a teoria do valor reconhece o papel crescente da ciência, mas ressalta que a mesma encontra-se tolhida em seu desenvolvimento pela base material das relações entre capital e trabalho, não podendo, sob o capital, tornar-se a principal força produtiva no lugar do trabalho. As análises de Antunes (2002 e 2013) confluem com as de Mandel (1985) quando este argumenta que as escolhas sobre determinadas técnicas e não outras são feitas por razões de lucratividade pelos ramos específicos da indústria, ou melhor, pelas empresas líderes naqueles ramos, dependendo, portanto, das relações de poder no seio da sociedade capitalista.

Assim, a introdução de inovações tecnológicas e organizacionais no processo produtivo é uma constante no modo de produção capitalista e nada tem de natural, neutra ou autônoma. O processo de inovação deve ser compreendido no âmbito das diferentes práticas sociais que, por sua vez, são produto das relações de classe na luta pelo controle social do trabalho no capitalismo. Ele está inserido na dinâmica da luta de classes, sendo variável política e de controle social (MANDEL, 1985; ANTUNES, 2002; PREVITALI; FARIA, 2008; ANTUNES, 2013;). A necessidade da constante reorganização do processo produtivo ocorre justamente como necessidade de combater a resistência dos trabalhadores ao controle e à racionalização (BRAVERMAN, 1981).

Portanto, o grande limite da abordagem neo-schumpeteriana está no fato de não articular o conceito de paradigma tecnológico e mesmo da mudança técnica à lei do valor, que é o que fundamenta historicamente o dinamismo tecnológico na ordem do capital.

\section{AS NOVAS RELAÇÕES LABORAIS: QUALIFICAÇÃO E PRECARIZAÇÃO}

A nova ordem de acumulação capitalista ancora-se em relações laborais fundadas na flexibilidade e no uso intensivo das tecnologias informacionais, nas exigências de maior escolarização e qualificação profissional, na redução expressiva do trabalho estável e contratado regularmente, concomitantemente ao aumento do emprego parcial, temporário, subcontratado e precário. Na União Europeia, a proporção de trabalhos temporários involuntário aumentou cerca de $1 \%$ entre 2008 e 2012 enquanto a percentagem de trabalhos a tempo parcial aumentou 2,4\% (ILO, 2014).

Em 2013, a média europeia de trabalho em regime parcial foi de 19,5\%, sendo mais uma regra que uma exceção na economia. Países como a Holanda, o emprego em tempo parcial chega a $50 \%$ do emprego total, o que significa que um em cada dois trabalhadores holandeses são empregados nesse tipo de regime de trabalho. Com taxas que ultrapassam a média europeia estão também a Alemanha (26,2\%), Áustria $(25,7 \%)$, Reino Unido (25,5\%), Dinamarca e Suécia (24,7\%), Bélgica (24,3\%), e Irlanda (23,5\%). Entre os países com mais de $10 \%$ de emprego a tempo parcial estão o Luxemburgo (18,7\%), França $(18,1 \%)$, Itália $(17,7 \%)$, Espanha $(15,9 \%)$. Em Portugal a taxa de emprego em regime parcial foi de $10,9 \%$. 
Segundo a OIT (2013), há atualmente 202 milhões de pessoas desempregadas no mundo. Dentre os setores econômicos que mais sofreram com o desemprego, destaca-se a indústria. Só nos Estados Unidos houve uma redução da classe trabalhadora nas indústrias na ordem de 35\% no período 1990 a 2010 (Gráfico 1).

\section{Gráfico 1 - Numero de Trabalhadores nos Estados Unidos na Indústria:} 1990-2010.

Number of employees in U.S. manufacturing from 1990 to 2010 (in millions)

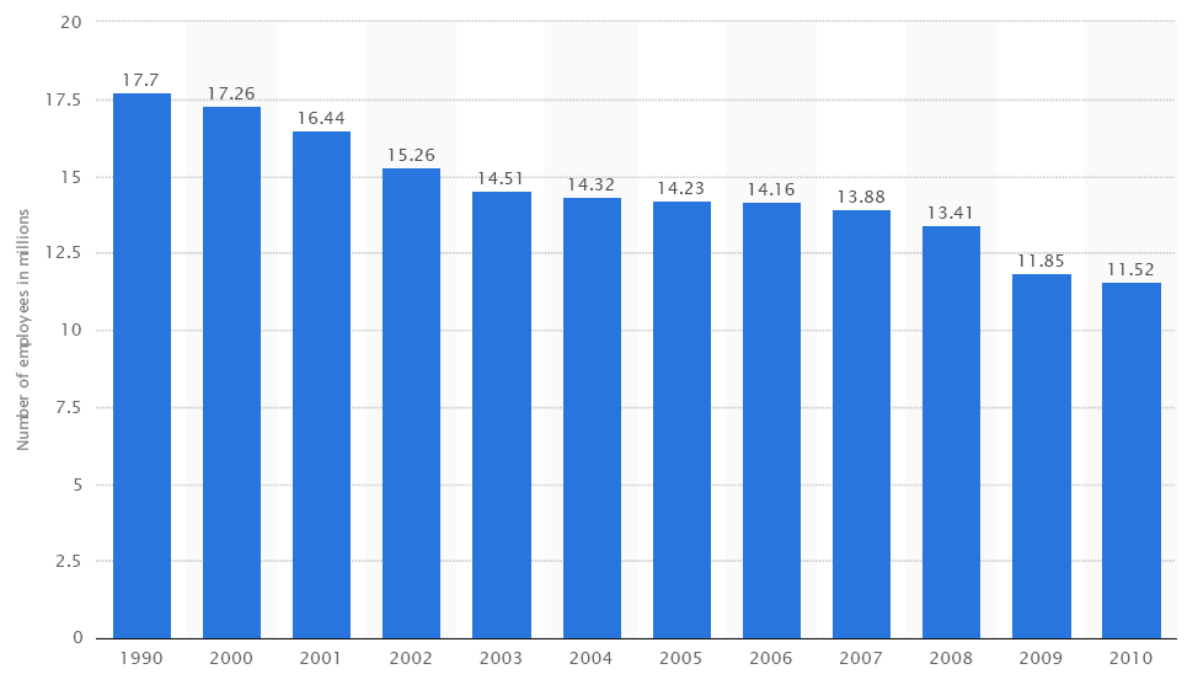

Fonte: Statista 2014.

O desemprego, juntamente com as políticas neoliberais de desregulamentação, impôs fortes derrotas ao movimento sindical que havia nascido sob as práticas tayloristasfordistas. No caso dos Estados Unidos, entre 2000 e 2012, as taxas de sindicalização foram reduzidas em 2,4\% (Gráfico 2).

Gráfico 2 - Porcentagem de Trabalhadores Sindicalizados nos Estados Unidos: 2000-2012 Percentage of employees represented by unions in the United States from 2000 to 2012

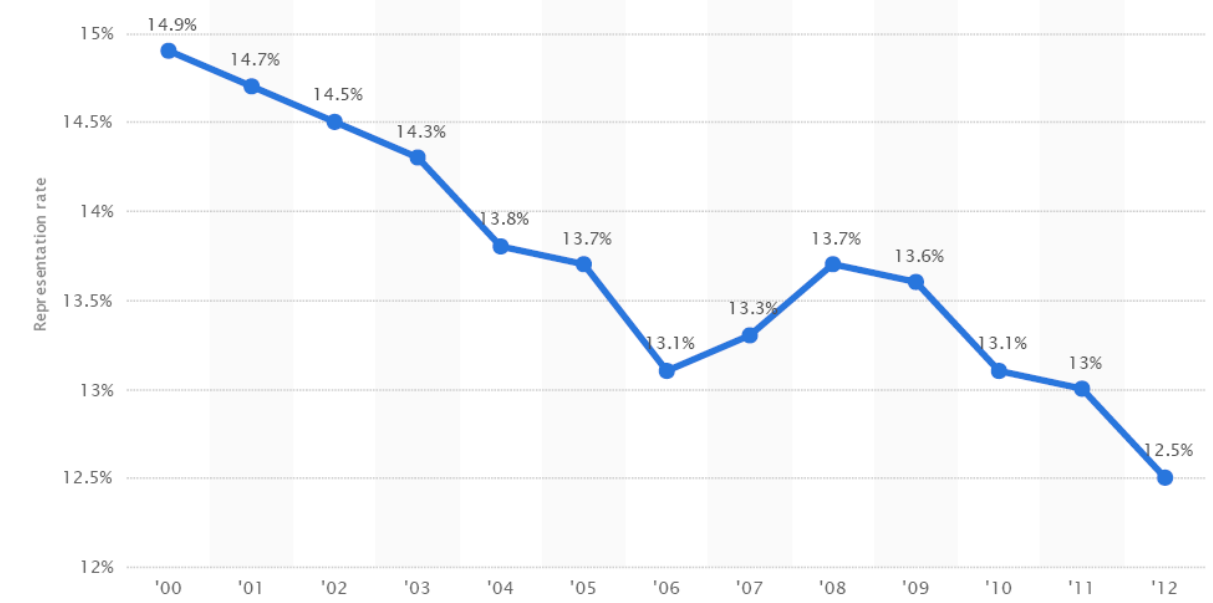

Fonte: Statista 2014.

Vale dizer que desde o final dos anos 1980 as empresas estão modificando suas relações com a classe trabalhadora. A reestruturação produtiva tem implicado na tendência à redução do proletariado industrial, estável e especializado, que se desenvolveu na 
vigência do taylorismo-fordismo (ANTUNES, 2002; ANTUNES, 2013; PREVITALI; FARIA, 2008; CARTER, et al, 2014). Simultaneamente, observa-se a formação de novas relações inter-firmas ao longo das mais diversas cadeias produtivas via processos de desverticalização, horizontalização e desconcentração do espaço físico produtivo, envolvendo práticas como a da terceirização e subcontratação, do trabalho temporário ou em curto prazo e em tempo parcial (VARELA, 2013; ANTUNES, 2002; ANTUNES, 2013).

As novas relações laborais tem imposto aos trabalhadores um intenso e cuidadoso monitoramento eletrônico por meio das análises constantes de índices de produtividade, de desempenho, de satisfação, entre outras, sendo apresentada sob a celebração da qualificação do trabalhador e de sua maior inserção intelectual no trabalho. A partir dos anos 1990 e fundamentalmente na década atual, apresenta-se uma tendência ao crescimento de trabalhadores em tempo parcial (part time) e concomitante redução dos trabalhadores em tempo integral (full time) nos países da Organização para Cooperação e Desenvolvimento Econômico (OCDE), como pode ser observado no Gráfico 3.

Gráfico 3 - Porcentagem (\%) da média de trabalhadores jovens (15-29 anos) empregados Full Time e Part Time entre 2006 e 2011 nos países da OCDE (sem Japão)

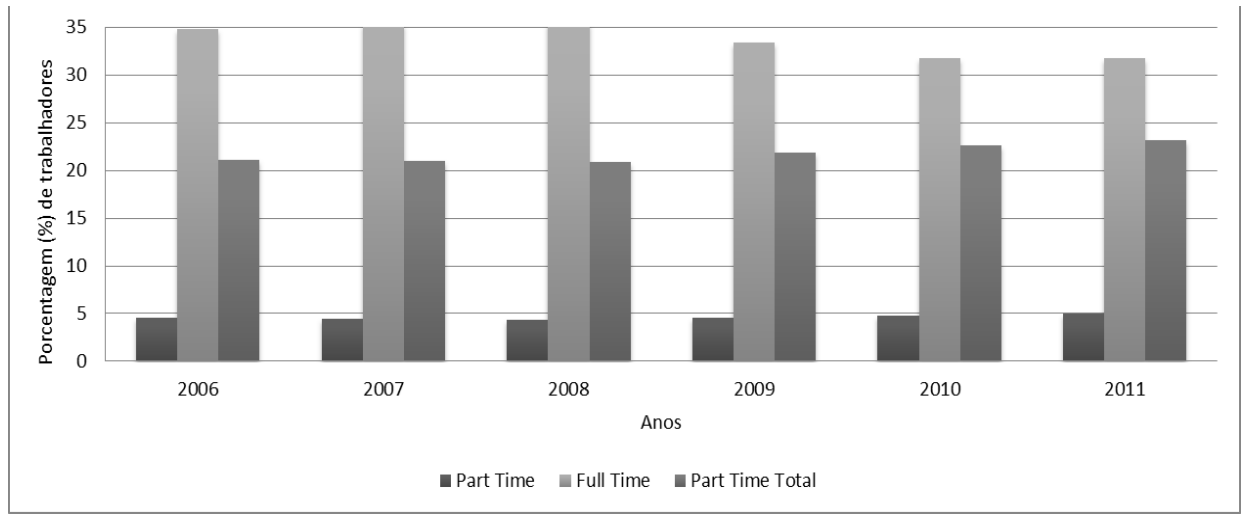

PPart Time Total - Relação com o numero total de trabalhadores

Fonte - Gráfico elaborado a partir do relatório da OCDE Education at a Glance 2013.

Especificamente nos Estados Unidos, o número de trabalhadores part time apresentou um aumento de aproximadamente 37\% entre 1990 e 2013 (Gráfico 4). 


\section{Gráfico 4 - Número de Trabalhadores em Tempo Parcial nos Estados Unidos:1990 a 2013 \\ Number of part-time employees in the United States from 1990 to 2013 (in millions)}

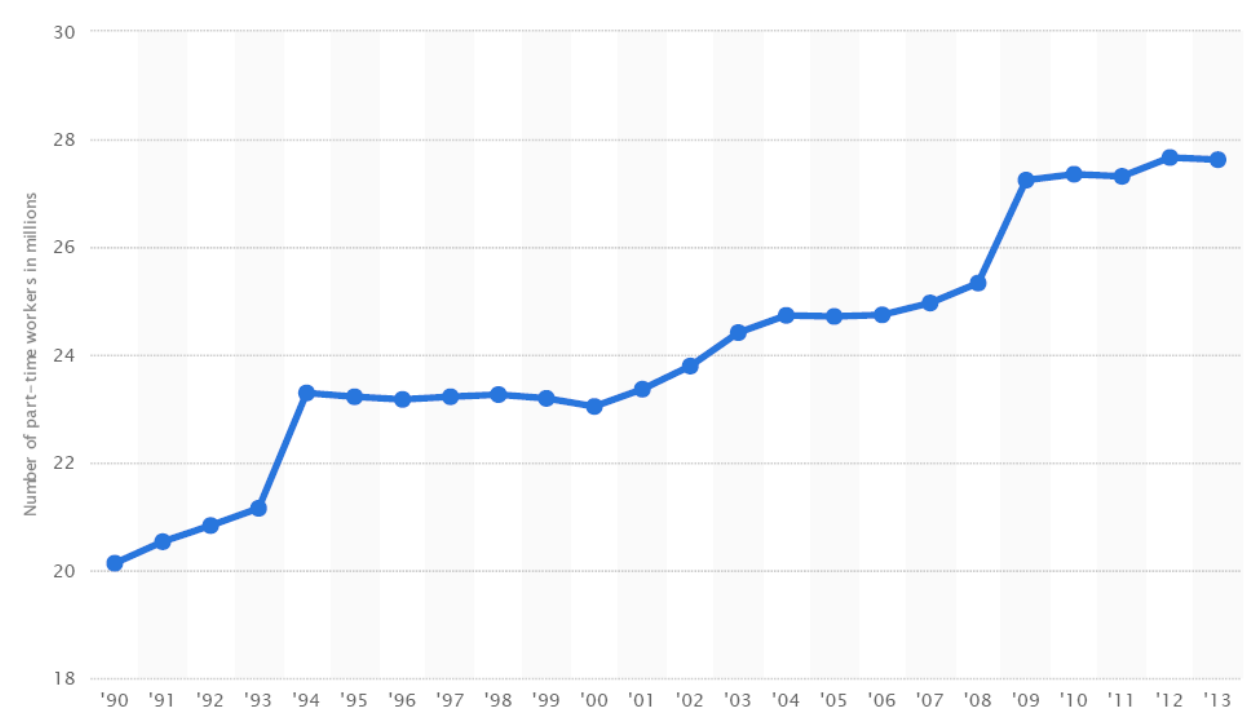

Fonte: Statista 2014.

Essas estratégias, que correspondem às formas de controle do trabalho e dos sindicatos no âmbito das lutas de classes (BRAVERMAN, 1981), levam à fragmentação da força de trabalho, bem como ao achatamento dos níveis salariais, à desregulamentação do trabalho em nome da flexibilidade e à conseqüente redução dos direitos trabalhistas. Segundo relatório da OIT (2013), dentre os trabalhadores empregados mundialmente, 375 milhões ganham menos de US\$ 1,25 por dia e outros 839 milhões recebem salários inferiores a US\$2. Nos Estados Unidos, 95\% do crescimento gerado após a crise de 2008 ficou nas mãos de $1 \%$ da população. Em Nova York, a grande maioria dos funcionários públicos trabalha sem contratos e os sindicatos que os representam têm sido incapazes de obter aumentos salariais e benefícios desde a crise de 2007-2008 (MILKMAN; LUCE, 2013).

Ao mesmo tempo a concentração de renda no mundo tem aumentado em níveis não vistos desde o início do século XX (HARVEY, 2011; MILKMAN; LUCE, 2013), o que tem implicado no aprofundamento da desigualdade de renda. De acordo com a OIT (2013), cerca de $10 \%$ da população mundial controla $86 \%$ dos ativos do planeta. Os $70 \%$ mais pobres controlam apenas $3 \%$. As 85 maiores fortunas do mundo somam US\$1,7 trilhão, a mesma renda de metade da população. "As elites globais estão mais ricas e a maioria da população mundial está excluída" (s/p), diz o relatório. Os dez países mais ricos da Europa mantêm fortunas equivalentes a todos os pacotes de resgate aos países da região entre 2008 e 2010.

Cumpre ressaltar que a classe trabalhadora tem aumentado significativamente nas sociedades contemporâneas, contrariando as teses que advogam o fim do trabalho e sua substituição pela técnica. O que se observa a partir das últimas décadas do século XX e início do século XXI é a construção de uma nova forma de racionalização do processo de trabalho. Nesse novo contexto, as mudanças tecnológicas e/ou organizacionais associadas ao toyotismo são apresentadas como as mais eficientes e racionais para o desempenho do processo produtivo, assim como a oportunidade de romper com os indesejáveis excessos da organização taylorista-fordista (PIORE; SABEL, 1984; WOMACH; JONES; ROSS, 
1989) uma vez que estariam possibilitando a recuperação da inteligência do trabalhador no local de trabalho.

Nos Estados Unidos o crescimento do emprego foi de aproximadamente $20 \%$ no período 1990 a 2012 (Gráfico 5).

Gráfico 5 - Nível de Emprego nos Estados Unidos: 1990-2012

Employment level of the United States from 1990 to 2012 (in millions)

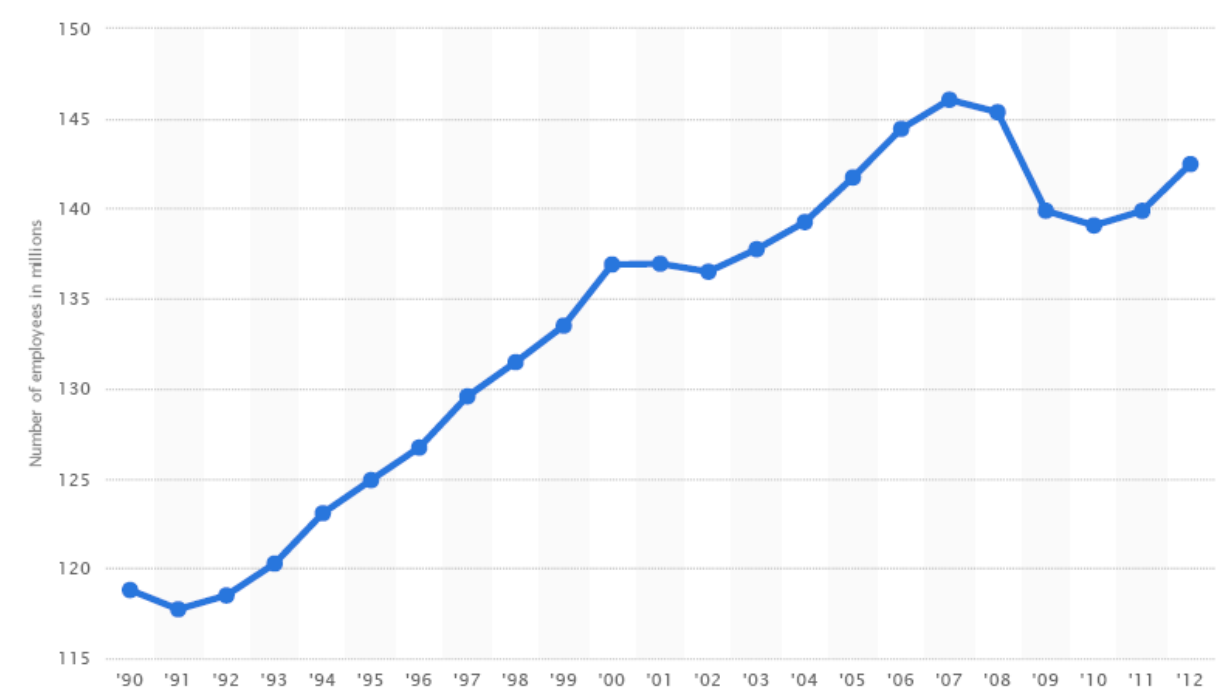

Fonte: Statista 2014.

O que se tem presenciado é a formação de um novo modelo produtivo que tem gerado emprego associado às novas tecnologias, porém, com menores salários e em piores condições de trabalho, contribuindo enormemente para a concentração de renda.

De acordo com o Banco Mundial e FMI, o número de trabalhadores em escala global apresentou uma elevação de $70 \%$, especialmente nos setores ligados à prestação de serviços, destacando-se a construção civil e de empregados domésticos (Tabela 1). No caso de Portugal, embora o governo apresente um discurso de diminuição de trabalhadores na máquina pública, o que se observa é a substituição de servidores concursados estáveis por servidores contratados por tempo determinado, implicando na precarização das relações laborais. No primeiro semestre de 2013, tanto a Administração Central como o Ministério da Economia e Emprego, aumentaram substancialmente o número de trabalhadores contratados. 
Tabela 1 - Crescimento da Classe Trabalhadora no Mundo entre 2002 e 2013 por setores econômicos e países

\begin{tabular}{|c|c|c|c|}
\hline Fonte & $\begin{array}{l}\text { Ano e número de } \\
\text { trabalhadores }\end{array}$ & Setor & Abrangência \\
\hline Site statista.com & $\begin{array}{l}2002-3.505 .919 \\
2013-4.064 .147\end{array}$ & Fast food & Estados Unidos \\
\hline Site MTE & $\begin{array}{l}2006-1.388 .958 \\
2011-2.762 .156\end{array}$ & Construção Civil & Brasil \\
\hline $\begin{array}{l}\text { ITUC (site the } \\
\text { guardian) }\end{array}$ & $\begin{array}{l}2013-1.2 \text { milhões } \\
2022-2.2 \text { milhões }\end{array}$ & Construção Civil & Qatar \\
\hline $\begin{array}{l}\text { DGAEP (site diário } \\
\text { liberdade) }\end{array}$ & $\begin{array}{l}10 . \operatorname{sem} .2013 \\
\text { (contratos) } \\
+6912(>68,5 \%) \\
+7107(>101,5 \%)\end{array}$ & $\begin{array}{l}\text { Emprego Público } \\
\text { (Administração central } \\
\text { e Ministério da } \\
\text { economia e emprego) }\end{array}$ & Portugal \\
\hline PORDATA & $\begin{array}{l}1998-4.844 \text { milhões } \\
2012-4.635 \text { milhões }\end{array}$ & População empregada & Portugal \\
\hline Site ISS & $2013-530.000$ & Serviços & $\begin{array}{l}\text { Mundial (60 } \\
\text { paises) }\end{array}$ \\
\hline $\begin{array}{l}\text { Apple (site } \\
\text { statisticbrain) }\end{array}$ & $\begin{array}{l}2009-34.300 \\
2010-46.600 \\
2011-60.400\end{array}$ & Informática & Mundial \\
\hline OIT (site bbc) & $\begin{array}{l}1995-33 \text { milhões } \\
2010-53 \text { milhões }\end{array}$ & Domésticas & $\begin{array}{l}\text { Mundial (sem } \\
\text { dados da China) }\end{array}$ \\
\hline $\begin{array}{l}\text { Banco Mundial / } \\
\text { FMI }\end{array}$ & $\begin{array}{l}1980-2.0 \text { bilhões } \\
2005-3.4 \text { bilhões }\end{array}$ & $\begin{array}{l}\text { Formal, informal, } \\
\text { empregados, } \\
\text { desempregados, } \\
\text { permanentes e } \\
\text { temporários. }\end{array}$ & Mundial \\
\hline $\begin{array}{l}\text { Banco Mundial / } \\
\text { FMI }\end{array}$ & $\begin{array}{l}1980-225 \text { milhões } \\
2005-900 \text { milhões }\end{array}$ & Global workers & Mundial \\
\hline \multicolumn{4}{|c|}{$\begin{array}{l}\text { MTE - Ministério do Trabalho e Emprego OIT - Organização Internacional do Trabalho } \\
\text { ITUC - International Trade Union Confederation DGAEP - Direção Geral da Administração e do } \\
\text { Emprego Público } \\
\text { Global workers - Trabalhadores envolvidos com mercadorias e serviços p/ exportação ou que emigram }\end{array}$} \\
\hline
\end{tabular}

Fonte: A partir de dados dos sites indicados na tabela.

Sob a égide do trabalho multifuncional, combinam-se, $\mathrm{m}$ muitas vezes no mesmo local de trabalho, trabalhadores estáveis e terceirizados, labor intelectual e esforço manual (PREVITALI; MORAIS; FAGIANI, 2013; ANTUNES, 2002; ANTUNES, 2013; CARTER et al, 2014).

$\mathrm{O}$ trabalho altamente qualificado e intelectualizado fundado na mais valia relativa combina-se ainda, de forma complexa e contraditória, com o trabalho em condições de super-exploração e de precarização, intensivo na extração da mais valia absoluta, ao longo das mais diversas cadeias produtivas, de que é exemplo a agroindústria sucroalcooleira (PREVITALI; MORAIS, FAGIANI, 2013).

Assim, umas conjugações de elementos que incluem formas flexíveis de emprego e elementos subjetivos comportamentais se tornam fundamentais para assegurar o controle, a disciplina e o consentimento desse novo trabalhador no local de trabalho e também fora dele, uma vez que, a partir da nova configuração das bases materiais de produção estabelecem-se novas formas de relações sociais, culturais e educacionais.

Kuenzer (2003) ressalta que as características demandadas pelo novo trabalhador flexível envolvem o desenvolvimento de competências cognitivas superiores e de relacionamento, tais como: análise, síntese, criatividade, rapidez de resposta, comunicação clara e precisa, interpretação e uso de diferentes formas de linguagem, capacidade para trabalhar em grupo e de liderar, gerenciar processos para atingir metas, trabalhar com prioridades, avaliar, lidar com as diferenças, enfrentar os desafios das mudanças permanentes e buscar aprender permanentemente. 
A luta por especialização é incentivada pela ideia de que o novo trabalhador deve ser mais escolarizado e qualificado. A nova educação orienta-se pelo conceito de multifuncionalidade, flexibilidade e empregabilidade, tendo como consequência um processo de individualização da formação do trabalhador, pelo qual se indica que cada um é responsável por buscar suas competências, a serem alcançadas, segundo o ideário neoliberal, com o desenvolvimento das habilidades básicas, específicas e de gestão (MACIEL; PREVITALI, 2011).

Braverman (1981), afirma que o termo qualificação sugere o domínio de uma técnica apreendida após anos de treinamento. $\mathrm{O}$ autor cita o exemplo do cocheiro que além de ter habilidade com os animais precisava entender de carroça, do manejo de ambos, etc. Entretanto, ainda que o tempo necessário para tornar-se um bom cocheiro fosse muito maior do que o necessário para tornar-se motorista, este último é considerado mais qualificado.

Isso porque, com destaca Braverman (1981), a valorização da qualificação está sempre atrelada às necessidades momentâneas do mercado e não a apropriação de algum ofício, e, mais ainda, não traz nenhuma garantia de emprego para o trabalhador. Para o autor, trabalho qualificado/complexo vale como trabalho superior ao desqualificado/simples porque é a exteriorização da força de trabalho na qual entram os custos mais altos de formação, cuja produção custa mais tempo de trabalho, e por isto tem valor mais elevado. Se o valor desta força de trabalho é superior, ela se objetiva, nos mesmos períodos de tempo, em valores proporcionalmente mais altos.

\section{CONCLUSÃO}

Como discutido acima, a inovação técnica deve ser compreendida como relacionada a diferentes práticas sociais que, por sua vez, são produto das relações de classe na luta pelo controle do trabalho no capitalismo, uma vez que este é que gera o valor. A mola propulsora do capitalismo é o trabalho, que cria a tecnologia. Esta, por sua vez, tem seu potencial restringido pela sua determinação de classe, subordinada aos imperativos do processo de criação de valores de troca.

A realidade do local de trabalho vem sendo marcada por mais intensificação, flexibilização e precarização das condições de trabalho, exigindo-se do trabalhador flexível submissão às jornadas de trabalho prolongadas, às horas extras sem pagamento, pois se tornam bancos de horas para serem tiradas em folga quando a empresa precisar reduzir a produção, multifuncionalidade para executar diferentes tarefas e operar vários tipos de máquinas e equipamentos, além de aptidões que favoreçam a iniciativa, a cooperação e o trabalho em grupos.

Na medida em que o número de trabalhadores se eleva e a oferta de empregos diminui, intensifica-se a concorrência entre eles, tornando-a tanto maior, mais inatural e mais violenta. Por outro lado, o capitalista beneficia-se dessa concorrência intra-trabalho empregando os mais qualificados por menores salários e benefícios, contribuindo para perda do sentimento de classe dos trabalhadores e para o achatamento generalizado da sua renda (MARX, 2010).

A consequência mais evidente desse processo é a crescente de individualização do trabalhador, fragilizando-o socialmente e contribuindo para o enfraquecimento das ações sindicais, ao mesmo tempo em que se torna fundamental a construção coletiva de novas 
práticas de resistência. Assim, as teses que advogavam a perda do significado do trabalho na sociedade estão longe de serem confirmadas.

O grande desafio que se apresenta hoje, tanto na teoria quanto na prática, está em apreender a relação de produção especificamente capitalista e compreender como vem ocorrendo o processo de exploração nas relações produtivas, buscando desmistificar as concepções de reintegração entre trabalho mental e manual, de substituição do trabalho pela ciência e de mais qualificação.

Para concluir, a realidade do trabalho contemporâneo resulta da forma que se desenvolve sob o capitalismo: a atividade humana é substituída pela máquina, "[...] mas lança parte dos trabalhadores de volta a um trabalho bárbaro e faz da outra parte máquinas" (MARX, 2010: 82).

\section{Referências}

ANTUNES, R. A Classe Trabalhadora Hoje e a Nova Morfologia do Trabalho: informalidade, infoproletariado, imaterialidade e valor, In: Varela, R. (coord). A

Segurança Social é Sustentável. Lisboa: Bertrand Editora. 2013. p. 337-362.

ANTUNES, R. Os Sentidos do Trabalho. São Paulo: Boitempo. 2002.

APPLE COMPUTER COMPANY STATISTICS. (2014). Disponível em: http://www.statisticbrain.com/apple-computer-company-statistics/. Acesso: 13 Jan. 2014.

BIHR, A. Da Grande Noite à Alternativa: o movimento operário europeu em crise. São Paulo: Boitempo. 1988.

BRAVERMAN, H. Trabalho e Capital Monopolista. Rio de Janeiro: Zahar. 1981.

CADASTRO GERAL DE EMPREGADOS E DESEMPREGADOS (CAGED) DO MINISTÉRIO DO TRABALHO E EMPREGO. Disponível em: http://www.mte.gov.br. Acesso: 08 Jan. 2014.

CARTER et al. They can't be the buffer any longer': front-line managers and class relations under white collar lean production. Capital \& Class. Vol. 38. N. 2. 2014. p. 323 -343. Disponível em: http://cnc.sagepub.com/content/38/2/323. Acesso: 25 Mar. 2014.

COGGIOLA, O; MARTINS, J. Dinâmica Da Globalização: Mercado Mundial E Ciclos Econômicos (1970-2005). UFSC. 2006. Disponível em:

http://arnobiorocha.com.br/wp-content/uploads/2012/02/livrocoggiolamartins.pdf . Acesso:13 Fev. 2014.

18,7\% DO TRABALHO NO LUXEMBURGO É A TEMPO PARCIAL. CONTACTO, 9/05/ 2014. Disponível: http://www.wort.lu/pt/economia/eurostat-18-7-do-trabalho-noluxemburgo-e-a-tempo-parcial-536cc7d8b9b3988708026045 . Acesso: 14 Mai. 2014

FREEMAN, C.; PEREZ, C. Structural Crises of Adjustment, Business Cycles and Investiment Behaviour, In: DOSI et al (Eds). Technical Change and Economic Theory. London: Pinter Publishes. 1988. 
GLOBAL EMPLOYMENT TRENDS FOR YOUTH 2013: A generation at risk / International Labour Office - Geneva: ILO, 2013. Disponível em : http://www.ilo.org/global/research/global-reports/global-employment trends/youth/2013/lang--en/index.htm. Acesso: 23 Jan. 2014.

GLOBAL ESTIMATE OF FORCED LABOUR. Annual Report ILO (2012). Disponível em: www.ilo.org/forcedlabour. Acesso: 5 Jan. 2014.

GRANEMANN, S. Fundações Estatais: Projeto De Estado Do Capital. Disponível em: http://dceufpr.files.wordpress.com/2008/08/fundacoes-sara-granemann.pdf . Acesso em: 15 Abr. 2014.

HARVEY, D. Condição Pós-Moderna. São Paulo: Edições Loyola. 1992.

HARVEY, D. O Enigma do Capital: as crises do capitalismo. São Paulo: Boitempo. 2011.

HAYEK, F. O Caminho da Servidão. (E-book). $6^{\text {a }}$. Edição. Disponível em: http://www.mises.org.br/files/literature/O\%20CAMINHO\%20DA\%20SERVID\%C3\%83O \%20-\%20WEB.pdf. Acesso: 10 Jan. 2012.

INTRODUCTION TO ISS. Disponível em:http://www.issworld.com/en/aboutiss/introduction-to-iss/fact-sheet. Acesso: 18 Jan. 2014.

INTERNATIONAL LABOUR OFFICE (ILO). Global Employment Trends 2014. http://www.ilo.org/wcmsp5/groups/public/---dgreports/---dcomm/--publ/documents/publication/wcms_233953.pdf . Acesso: 16. Jan. 2014.

KUENZER, A. Z. Educação profissional: categorias para uma nova pedagogia do trabalho. Disponível em: http://www.senac.br/ BTS/252/boltec252b.htm. 2003. Acesso: 10 Fev. 2011.

MACIEL, R. M.; PREVITALI, F. S. Impacto das Políticas Públicas do Trabalhador da Educação na Rede Estadual de Ensino de Patos de Minas / MG em 2011. Revista Labor. vol. 1, n. 6. p. 326-343. 2011.

MANDEL, E. O Capitalismo Tardio. Coleção Os Economistas. São Paulo: Abril Cultural. 1985.

MARX, K. Manuscritos econômicos e filosóficos de 1844. Tradução Jesus Ranieri. São Paulo: Boitempo. 2010.

MARX, K. O Capital. Livro 1. São Paulo: Boitempo. 2013.

MAZZUCATO, M.; PEREZ, C. Innovation as Growth Policy: the challenge for Europe. Working Paper Series. SWPS 2014 - 13. 10 de Julho, 2014. P. 1-21. Disponível em: https://www.sussex.ac.uk/webteam/gateway/file.php?name=2014-13-swps-mazzucatoperez.pdf\&site $=25$. 2014. Acesso: 20 Julh. 2014.

MILKMAN, R. Farewell to the Factory: auto workers in the late twentieth century. Los Angeles: University of California Press, Barkeley. 1997. 
NUMBER OF EMPLOYEES IN THE US SINCE 1990. Disponível em: http://www.statista.com/statistics/192384/number-of-employees-in-the-us-since-1990. Acesso: 15 Jan. 2014.

NUMBER OF EMPLOYEES IN US FAST FOOD RESTAURANTS SINCE 2002. Disponível em: http://www.statista.com/statistics/196630/number-of-employees-in-us-fastfood-restaurants-since-2002/. Acesso: 15 Jan. 2014.

NUMBER OF EMPLOYEES IN US MANUFACTURING SINCE 1990. Disponível em http://www.statista.com/statistics/184562/number-of-employees-in-us-manufacturingsince-1990. Acesso: 10 Jan. 2014.

NUMBER OF PART TIME EMPLOYEES IN THE US SINCE 1990. Disponível em: http://www.statista.com/statistics/192338/number-of-part-time-employees-in-the-us-since1990. Acesso: 12 Jan. 2014.

OCDE INDICATORS. Disponível em: http://www.oecd.org/edu/eag2013\%20(eng)-FINAL\%2020\%20June\%202013.pdf. Acesso: 12 Jan. 2014.

PAÍSES EMERGENTES REÚNEM MAIOR NÚMERO DE DOMÉSTICAS. Disponível em: http://www.bbc.co.uk/portuguese/noticias/2013/04/130404_oit_emergentes_fl.shtml. Acesso: 15 Jan. 2014.

PERCENTAGE OF EMPLYOYEES RESPRESENTED BY UNIONS IN THE US SINCE 2000. Disponível em: http://www.statista.com/statistics/195341/percentage-ofemplyoyees-respresented-by-unions-in-the-us-since-2000/. Acesso: 10 Jan. 2014.

PEREZ, C. Technological revolutions and techno-economic paradigms, Cambridge Journal of Economics. vol. 34, n.1, p. 185-202. 2010. Disponível em: http://cje.oxfordjournals.org/content/34/1/185 . Acesso: 10 Nov. 2013.

PEREZ, C. Technological revolution and financial capital: the dynamics of bubbles and golden ages. London: Cheltenham/Elgar. 2002.

PIORE, M.; SABEL, C. The Second Industrial Divide - possibilities for prosperity. New York: Basic Books. 1984.

PORDATA AMBIENTE DE CONSULTA. Disponível em: http://www.pordata.pt/Portugal/Ambiente+de+Consulta/Tabela. Acesso: 18 Jan. 2014.

PORTUGAL: NÚMERO DE TRABALHADORES A RECIBOS VERDE NA ADMINISTRAÇÃO CENTRAL AUMENTA 68,3\%. Disponível em: http://www.diarioliberdade.org/portugal/laboral-economia/43198-portugaln\%C3\%BAmero-de-trabalhadores-a-recibos-verde-na-administra\%C3\%A7\%C3\%A3ocentral-aumenta-68,3.html. Acesso: 16 Jan. 2014.

PREVITALI, F. S.; MORAIS, S. P.; FAGIANI, C. C. Ethanol workers in Brazil: the other side of wealth. Workers of the World, vol. 1, n. 3, p. 227-245. 2013. 
PREVITALI, F. S.; FARIA, A. F. Reestruturação produtiva e novas formas de controle no local de trabalho: a experiência da indústria de fumo em Uberlândia-MG. Antíteses. vol. 1, n. 1.p. 95-117. 2008.

QATAR WORLD CUP MIGRANT WORKES DEAD. Disponível em:

http://www.theguardian.com/global-development/2013/sep/26/qatar-world-cup-migrantworkers-dead. Acesso: 18 Jan. 2014.

THOMPSON. P. The capitalist labour Process: concepts and connections.

and connections. Capital \& Class, vol. 34, n. 1. 2010. p. 7 - 14. Disponível em:

http://www.izt.uam.mx/sotraem/Bibliografia/Thompsonthecapitalist.pdf . Acesso: 04 Fev. 2010.

TOMANEY, J. A. New paradigm of Work Organization and Technology?, In: AMIN, A (Org). Post-Frodism. Oxfrod: Blackwell. 1990. p. 05-28.

VARELA, R. Ruptura e Pacto Social em Portugal (1974 - 2012), In: PREVITALI, F. S. (Org). Novos Contornos do Trabalho, Educação e Alienação no Século XXI. São Paulo: Xamã. 2013. p. 49 - 70.

WOMACK et al. The Machine that Changed the World. New York: Rawson Associates. 1990.

\footnotetext{
i Docente na Universidade Federal de Uberlândia (UFU). Investigadora no Instituto de História Contemporânea, Universidade Nova de Lisboa (IHC/UNL). Apoio Fapemig, CNPq e Capes (2013-2014). Coordenadora do Grupo de Pesquisa Trabalho Educação e Sociedade (GPTES) e-mail: fabianesp@ netsite.com.br

ii Doutorando no Programa de Pós-Graduação em Educação, Universidade Federal de Uberlândia (PPGED/UFU), linha de pesquisa Trabalho, Sociedade e Educação, apoio Fapemig. Doutorado Sanduíche no Instituto de História Contemporânea, Universidade Nova de Lisboa (IHC/UNL), apoio Capes (2013-2014). Membro do GPTES. e-mail: cilsoncf@netsite.com.br
}

Recebido: mai/2015 Aprovado: jun/2015 